\title{
JOURNAL COSTS: JOURNAL PUBLISHING AS PART OF A SOCIETYS OPERATIONS
}

\author{
Dr. Peter B. Boyce \\ American Astronomical Society
}

\section{Summary}

Scientific Societies have a broad range of goals, all aimed at advancing their area of science. Journal publishing is but one important task of a society. Subscription prices are normally set within the broad context of all the society's programs. By using a normalization procedure it is possible to evaluate the relative costs and effectiveness of journals. Normalized costs to libraries of scientific journals vary by nearly 100 -fold. In general, society published journals are very cost effective. In particular, the AAS journals rank among the leaders in terms of cost and effectiveness.

\section{Goals of a Scientific Society}

Scientific societies generally have been established for the purpose of advancing a particular branch of science. In response to this broad overall purpose, most scientific societies have set up a number of diverse programs designed to achieve various specific goals in support of their particular science. In general, the foremost goal of a society is to promote the communication of research results among the practitioners in the field. At present this is normally done by organizing scientific meetings and by publishing scientific journals. It is important to differentiate between the dissemination of research results, which is the goal, and the publication of journals, which, at present is the most effective way to achieve that goal. However, the time may come when journal publication, as it is now done, will no longer be the preferred way to inform one's colleagues about recent advances in the field.

A society which is narrowly focussed on dissemination of research results will not be effective in today's research environment. Other goals, and the programs to achieve them, are important. For instance, as most other societies do, the American Astronomical Society has a number of additional goals. These include providing information to the membership to keep them up to date on recent developments (AAS Newsletter), making communication with colleagues easier (AAS Membership Directory), providing centralized job services (AAS Job Register and Job Placement Centers), providing funds for research expenses (AAS Small Research Grant and International Travel Grant Programs), fostering excellence through a series of awards (Russell Lectureship and other awards), encouraging science education (Astronomer for a Day Program for high school teachers) and astronomy education (Shapley Visiting Lecture Program), and, finally, promoting an awareness of the science of astronomy among the public and within the federal government.

Above all, in order for a society to be effective, it must remain solvent and it must maintain a strong and active membership. Although scientific societies are committed to the highest intellectual activities, they must, in the end, operate in a businesslike manner. This includes making sufficient money from their income-producing activities to finance the important non-income programs and to keep the reserves at a prudent level. It is the task of the governing body of the society to evaluate the programs and the sources of income and balance the worth of each program against the prices needed in the form of dues, subscriptions and other charges to support the society's programs.

\section{Integrating Journals into a Society's Financial Structure}

An effective scientific journal must maintain scientific integrity and archival quality while at the same time reaching a broad audience. The pricing structure of the journal has to be integrated into the 
overall goals, needs and programs of the society. How this is done varies from one society to another. Some societies use income from journals to finance their other programs, thus keeping their dues low and encouraging the growth of a large membership and enhancing the overall effectiveness of the society. On the other hand, the AAS keeps the journal finances separate from other society programs and prices the journals at a level which is anticipated to be sufficient to cover the expenses and maintain the reserve funds of the journals. This keeps the price of the subscriptions low, but puts a burden on the members who pay higher dues than most other similar societies.

\section{Measuring the Effectiveness of Journals}

The sharply rising cost of scientific journals has become an item of concern, both within the library community and among societies, whose members are dependent upon those same research libraries. As described by Helmut Abt in this volume, there are several causes. More papers are being published, and journals are getting larger. The cost of journal production continues to rise, although substantial efforts to use new technology have kept this increase to a minimum. The number of subscriptions shows a small, steady decline. Fewer subscribers must pay for a total growing cost. Finally, the page charges have been reduced, or even eliminated, in many journals, forcing the subscribers to pick up a larger percentage of the total production cost.

Whatever the causes, libraries are being forced to prune their lists of journals. In making these choices it is important to consider more than the price of the subscription. Barschall (1) has argued that journal formats show a wide variation in the number of pages per volume and the number of characters per page. He computes a normalized cost, the cost to libraries per 1000 characters, and argues that this is the cost which should be considered in assessing the value of a publication. The results of applying Barschall's technique to astronomical journals is given in Figure 1 for the ten least expensive astronomy journals. There is a wide range in the normalized library subscription cost. For instance, the cost to libraries of the Astrophysical Journal is about five times cheaper than Astronomy and Astrophysics and ten times cheaper than Icarus. There are several other journals which are even more expensive.

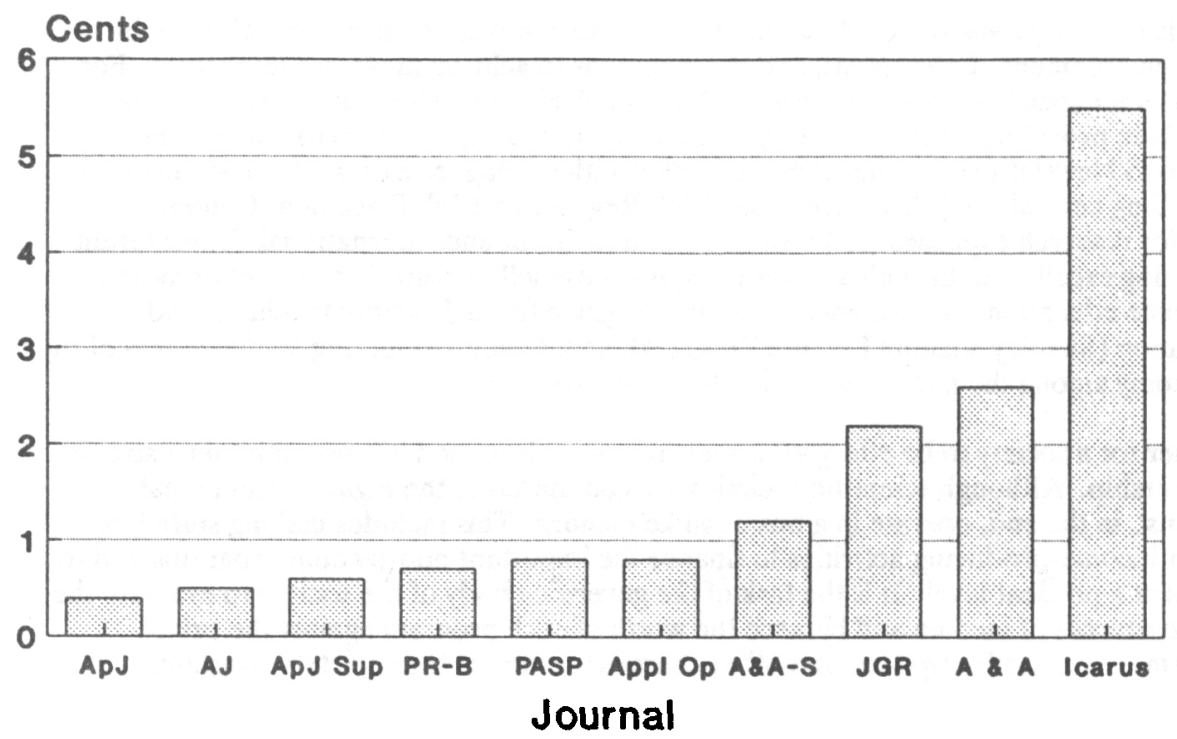

Figure 1: Cost of Journals to Libraries in Cents per 1000 characters (1985) Data collected by Peter B. Boyce 
In this comparison, the society journals have an advantage because they often charge the authors for manuscript preparation on a per page basis. Nevertheless, as pointed out by Barschall (1), the correction for this effect is small in comparison to the range of prices exhibited. For the Astrophysical Journal, which derives just over one-half its income from page charges to authors, the normalized cost to libraries would double or, at most, triple if no page charges were levied. The five-fold and ten-fold differences which occur can not be explained by differences in page charge policy.

However, the real value of a publication can not just be measured by the purchase cost. The importance and use of the contents must be factored in. Barschall has recently (2) expanded his study to include the number of citations which he combines with the cost to give a normalized cost/impact ratio. Barschall tabulates the cost/impact ratio for the publications of a number of societies. As shown in Figure 2, the publications of the AAS, taken as a whole, are the most effective of any surveyed by Barschall.

\section{Conclusion}

The publication of Journals is but one segment of a society's services to its membership and the scientific community it represents. Pricing strategies vary from publisher to publisher. In the case of the scientific societies, the goal is to achieve an overall program which will most effectively advance the field of science. Societies are aware of the budgetary pressures on research libraries and are working to minimize subscription costs while still maintaining sufficient income to cover the cost of publication. The success of the cost containment efforts of the AAS are evident in the low cost per character and low cost per citation reported here and in other recent studies.

\section{References:}

1. Henry H. Barschall, Physics Today, 39, 34, 1986

2. Henry H. Barschall, Physics Today, 41, 56, 1988

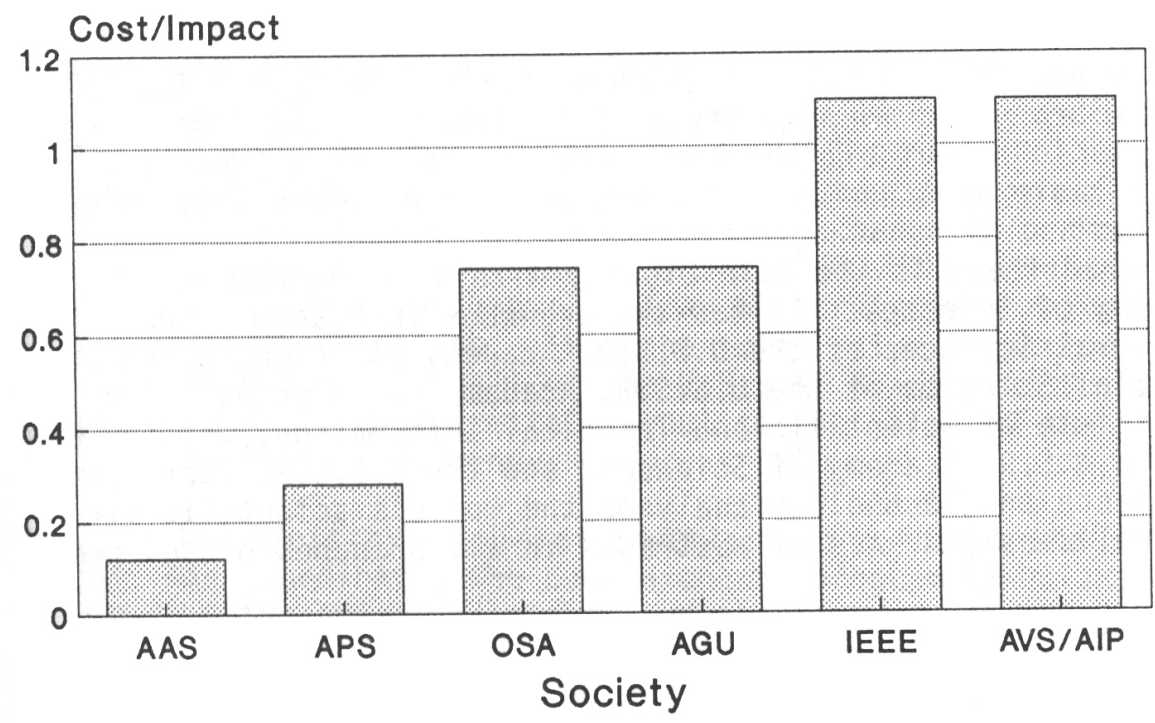

Figure 2: Average Cost/Impact Ratio: A comparison of Societies Data from Barschall (2) 